Article

\title{
A Constrained Production System Involving Production Flexibility and Carbon Emissions
}

\author{
Asif Iqbal Malik $(\mathbb{D}$ and Byung Soo Kim * (D) \\ Department of Industrial and Management Engineering, Incheon National University, 119, Academy-ro, \\ Yeonsu-gu, Incheon 22012, Korea; ai.asifiqbalmalik@gmail.com \\ * Correspondence: bskim@inu.ac.kr
}

Received: 15 January 2020; Accepted: 13 February 2020; Published: 19 February 2020

check for updates

\begin{abstract}
The proposed study presents an economic lot size and production rate model for a single vendor and a single buyer setup. This model involves greenhouse gas (GHG) emissions from industrial sources. The carbon emissions in this model are considered as two types: direct emissions and indirect emissions. The production rate affects carbon emissions generation in production, i.e., generally, higher production rates result in more emissions, which is governable in many real-life cases. The production rate also impacts the process reliability and quality. Faster production deteriorates the production system quickly, leading to machine failure and defective items. Such reliability and quality problems increase energy consumptions and supply chain (SC) costs. This paper formulates a vendor-buyer SC model that tackles these issues. It considers two decision-making policies: integrated or centralized as well as decentralized, where the aim is to obtain the optimal values of the decision variables that give the minimum total SC cost. It includes the costs of setup, holding inventory, carbon emissions, order processing, production, reworking, and inspection processes. The decision variables are the production rate, lead time, order quantity, the number of shipments, and the investments for setup cost reduction. In the later sections, this paper compares the numerical outcomes of the two centralized and decentralized policies. It also provides sensitivity analysis and useful insights on the economic and environmental execution of the SC.
\end{abstract}

Keywords: supply chain; flexible production; carbon emissions; direct and indirect emissions; optimal discrete investments

\section{Introduction}

Supply chain management (SCM) is defined by the Council of Supply Chain Management Professionals (CSCMP) (2004) as "the planning and management of all activities involved in sourcing and procurement, manufacturing processes, and all logistics management activities, including coordination and collaboration with suppliers, intermediaries, and customers" [1]. The production setup is an integral part of supply chain management (SCM). The flexibility in production setup makes the SCM flexible, which means the production rate, process, time, and lead time can be controlled. The production setup flexibility implies that the production rate can be altered as desired [2]. However, it loses flexibility when the carbon emissions are considered. The manufacturer can control its emissions by managing inventory, production, and transportations. With the flexible production system, the amount of carbon emission can change significantly. Automation is the key factor to flexibility in SCM, making sure that the system can be adequately and easily controlled [3]. The manufacturers can install cleaner (producing less emissions) generators, machines, and production setups to reduce direct carbon emissions. Meanwhile, manufacturers can utilize environmentally-friendly and cleaner energy resources to minimize indirect carbon emissions. This research focuses on production rate flexibility involving the consideration of carbon emissions. 
One of the primary lot-sizing decision variables is the production rate (or speed), impacting both the environmental performance and the quality of the production processes, such as energy consumptions and emissions generation. A variable production rate affects the quality of the processes, bringing extra costs. A higher production rate negatively impacts the reliability of the production system and increases the probability of producing defective items. The production process flexibility was introduced to the production models by Khouja and Mehrez [4] by considering the variable production rate. Further, it was not considered to be much for the production planning model. Last decade, Glock [2] considered the variable production rate to model an integrated model for the vendor buyer system. This work was further extended by the Glock [5] while considering batch size policy under the flexibility limits. Furthermore, Glock [6] advanced the work to the multi-stage production system. Moreover, in both proposed models [5,6] Glock et al. proved that the variable production rates significantly affect the waste reductions and the total cost in both single-stage and multi-stage production setups.

Recently, AlDurgam et al. [7] developed a two-echelon inventory model to tackle uncertainties in demand and lead time with the consideration of variable production rates. They proved the reductions in supply chain cost with flexible production rates and improved coordination among the SC members. Sarkar et al. [8] studied a multi-buyer single-vendor model for the stochastic lead time demands and variable production rates to control the SC cost. In a most recent study, a two-echelon model was proposed to reduce the setup cost and time with quality improvements under the stochastics conditions by Dey et al. [9]. Sarkar and Chung [3] analyzed the work-in-process production-inventory control model considering automation, lead time, and setup cost reductions with discrete investments. They introduced quality improvements with continuous investments to model as well. Some more studies on this topic can be found in reference [10]. However, the above-discussed production and supply chain models with variable production rates have not considered the important factor while introducing the flexibility to the production setup, and that is the budget limitations for the vendor. The vendor may not have the budget available for the production at some stage during the process. Therefore, there is an immediate need to consider the budget constraint in flexible production systems.

The issue of making a sustainable production system with energy efficiency was studied by Sarkar et al. [11]. Dehning et al. [12] analyzed the possibilities of energy demand reductions for production systems in production-down times. Further, an extensive literature review on energy-efficient production systems can be found in reference [13], while energy efficiency in SCM can be found in Marchi and Zanoni [14]. Marchi et al. [15] explored a possible coordination policy for the investments in energy-efficient technologies under the effects of learning curves. However, they have not considered carbon emissions in new technologies for optimized energy consumption. The energy consumption by industry sectors is affected by direct and indirect emissions. The direct emissions are produced from the activities entirely controlled by the manufacturer that are directly related to emissions, such as production processes, furnaces, and other equipment. The indirect emissions are results of manufacturer related activities but are generated by the sources beyond the manufacturer, and these emissions are associated with the amount of energy used and the utility supplying it such as purchased electricity, steam, heat, and cooling. The amount of carbon emissions can be determined at various manufacturing and related activities. The manufacturing industry is considered to be an important sector in economic growth. This sector is one of the leading factors in emission sources and energy consumptions. GHG emissions from the manufacturing industry in the US were reported as reaching $21 \%$ of the total emissions in 2014 (Wangsa [16]) and have increased in recent years (Environmental Protection Agency (EPA)).

A major portion of emissions from the manufacturing industry comes from fossil fuels for energy utilized to manufacture products from different raw materials. The energy usage of any industry is greatly affected by direct and indirect emissions. Wahab et al. [17] and Hua et al. [18] were among the few pioneers to work on carbon emissions in inventory and SC models. Wahab et al. [17] formulated different domestic SC and international SC models that assumed the environmental 
effects. Hua et al. [18] followed the emission constraints into the classical inventory model under the supposition that carbon emissions are a linear function of the order quantity. Benjaafar et al. [19] analyzed different emission constraints to the buyer's lot-sizing model, and Chen et al. [20] formulate the vendor-buyer model with the dynamic customers' demand under different emissions policies, i.e., an inflexible cap and a carbon tax. They studied the trade-off between carbon emissions and total costs. Further, Jaber et al. [21] studied a two-level SC involving integrating a carbon tax and penalties to cut down the amount of emissions produced. They considered that the amount of emissions is a direct function of the optimal production rate.

Bazan et al. [22] investigated the consignment stock policy of vendors by mathematically formulating the two-echelon SC model that studied the energy used and carbon emissions during the production process. Further, Bazan et al. [23] studied the two-level closed-loop SC model that considered carbon emissions and different coordination policies among the manufacturer and retailer. Wangsa [16] analyzed the vendor-buyer SC model using incentive and penalty policy to cut down the amount of carbon emissions. They considered the direct and indirect sources of emissions for the production process under partial backordering and normally distributed buyer's demand. Micheli and Mantella [24] formulated the inventory routing model with carbon control and uncertain customer demand. They considered and analyzed the environmental and economic significances for four policies: a carbon tax, cap, cap-and-offset and cap-and-trade. Aljazzar et al. [25] developed the two-echelon model to investigate and optimize the economic and environmental performance of the SC by considering delayed payments as the coordination policy for the buyer and manufacturer. Recently, Marchi et al. [26] studied environmental impacts in a two-level SC model with different coordination policies. They analyzed the optimal production rates concerning the amount of emissions produced and process quality. Daryanto et al. [27] analyzed the retailer-manufacturer coordination SC model for deterioration products in an imperfect manufacturing system. They considered the cost of emissions for the warehousing and transporting the items.

In the current competitive business and SC world, each competing industry likes to get more profit with fewer investments. The classical models (EOQ and EPQ) consider the lead time and the setup cost are fixed parameters in the modeling. However, these two factors can be reduced with investments, which can play a crucial role in the economic performance of any company and SC management. Gholami-Qadikolaei [28] studied the SC model with ordering cost and lead time control under the space and budget limitations. They considered the normally distributed probabilistic demand during the lead time. Malik and Sarkar [29] studied the inventory problem under uncertain demands and with service level constraints. They considered the setup cost reductions and quality improvements with continuous investments. Shin et al. [30] analyzed the SC model under stochastic demands, service level constraints and lead time control with additional costs. Recently, Malik and Sarkar [31] studied the SC models while considering lead time and setup cost reductions with discrete investments. With lead time reductions, the service level can be improved, and customers' satisfaction may help management to increase their profits. Dey et al. [9] proposed a recent study on the setup cost and time reductions in two-level SC management. They considered that the lead time demand is normally distributed, and shortages are partially backordered. However, in a real-life business, it is hard to get exact information about the demand distribution. Further, these models did not consider the flexibility in production systems i.e., the variable production rates. To achieve this, in this model, the authors introduced the distribution-free approach for the limited information about lead time demand. In addition, we considered the service level for customer demands in terms of the demand fill rate (see references [30,32,33]). The comparison to the literature and authors' contributions are given in Table 1.

Recently, many researchers proposed different types of SC models under the imperfect conditions, reworks for defective products, shortages and setup cost reductions (see for reference [3,34-36]). However, no one has considered a model for a vendor-buyer SC system with consideration of a service level, unknown lead time demand distribution and an optimal production rate and cost along 
with discrete investment for setup cost reduction for the vendor and the carbon emission from the manufacturing process in terms of direct and indirect emissions. In addition to this, no one has considered the budget constraint for the vendor with a variable production rate-further, the space constraint for the buyer under the consideration of a fixed service level. There exists a significant research gap in this direction, which is fulfilled by this proposed study. To fulfill the identified research gap, the authors in this study proposed research on the flexible production system with a variable production rate and production cost, investments to reduce the lead time and a setup cost. In addition to this, this study considered the direct and indirect carbon emissions from the production system with the variable production rate to identify the environmental impact of a higher or lower production speed (rate). Further, this study incorporates the budget constraints for the vendor and the space constraint for the buyer while considering the variable production rate and the customers' service level. 
Table 1. Author(s) contribution in comparison to literature.

\begin{tabular}{|c|c|c|c|c|c|c|c|c|c|}
\hline \multirow{2}{*}{ Author(s) } & \multirow{2}{*}{ Model Type } & \multirow{2}{*}{$\begin{array}{c}\text { Variable } \\
\text { Production Rate }\end{array}$} & \multirow{2}{*}{$\begin{array}{l}\text { Stochastic } \\
\text { Demand }\end{array}$} & \multirow{2}{*}{$\begin{array}{l}\text { Lead Time } \\
\text { Control }\end{array}$} & \multicolumn{3}{|c|}{ Constraints } & \multirow{2}{*}{ Carbon Emission } & \multirow{2}{*}{ Investment Type } \\
\hline & & & & & Service Level & Space & Budget & & \\
\hline Khouja and Mehrez [4] & Production & $\checkmark$ & & & & & & & NA \\
\hline Tajbakhsh [32] & Inventory & & $\checkmark$ & & $\checkmark$ & & & & NA \\
\hline Glock [6] & Production & $\checkmark$ & & & & & & & NA \\
\hline Pasandideh et al. [37] & SCM & & & & & & $\checkmark$ & & NA \\
\hline Jamshidi et al. [38] & SCM & $\checkmark$ & & $\checkmark$ & & & & & NA \\
\hline Sarkar et al. [33] & Production & & $\checkmark$ & $\checkmark$ & $\checkmark$ & & & & Continuous \\
\hline Bazan et al. [22] & SCM & $\checkmark$ & & & & & & $\checkmark$ & NA \\
\hline Gholami-Qadikolaei et al. [28] & Inventory & & $\checkmark$ & $\checkmark$ & & $\checkmark$ & $\checkmark$ & & NA \\
\hline Shin et al. [30] & SCM & & $\checkmark$ & $\checkmark$ & $\checkmark$ & & & & NA \\
\hline Sarkar et al. [39] & SCM & & & & & & & $\checkmark$ & Discrete \\
\hline Wangsa [16] & SCM & & & & & & & $\checkmark$ & NA \\
\hline AlDurgam et al. [7] & SCM & $\checkmark$ & & & & & & & NA \\
\hline Malik and Sarkar [29] & Inventory & & $\checkmark$ & $\checkmark$ & $\checkmark$ & $\checkmark$ & & & Continuous \\
\hline Aljazzar et al. [25] & SCM & $\checkmark$ & & & & & & $\checkmark$ & NA \\
\hline Sarkar et al. [8] & SCM & $\checkmark$ & $\checkmark$ & & & & & & NA \\
\hline Malik and Sarkar [40] & SCM & & $\checkmark$ & $\checkmark$ & & & & & Discrete \\
\hline Marchi et al. [26] & SCM & $\checkmark$ & & & & & & $\checkmark$ & NA \\
\hline Sarkar and Chung [3] & SCM & $\checkmark$ & & & & & & & Discrete \\
\hline This Model & SCM & $\checkmark$ & $\checkmark$ & $\checkmark$ & $\checkmark$ & $\checkmark$ & $\checkmark$ & $\checkmark$ & Discrete \\
\hline
\end{tabular}

SCM: Supply chain management; NA: Not applicable to the study. 


\section{Notation and Assumptions}

The following notation have been used to develop the mathematical model for the proposed problem in this paper.

The decision variables are

$\begin{array}{ll}Q & \text { order quantity } \\ P & \text { production rate } \\ \eta & \text { number of shipments } \\ Z & \text { investment to reduce setup cost } \\ L & \text { lead time } \\ R & \text { the reorder point } \\ \rho_{\varphi} & \text { safety factor }\end{array}$

Parameters to formulate the mathematical model are

$\begin{array}{cl}A & \text { ordering cost for the buyer } \\ R & \text { reorder point for the buyer } \\ D & \text { demand } \\ h_{b} & \text { holding cost for the buyer } \\ C(L) & \text { lead time crashing cost } \\ \varphi & \text { service level } \\ \sigma & \text { standard deviation for the demand during lead time } \\ S_{w} & \text { available storage space at the buyer's place } \\ S & \text { space required for unit product } \\ E(X-R)^{+} & \text {expected value of demand during the lead time } \\ S_{0} & \text { setup cost before the reduction investments } \\ h_{M} & \text { holding cost for vendor } \\ C_{i} & \text { inspection cost } \\ M & \text { raw materials cost } \\ E_{C P} & \text { energy and labor cost } \\ \tau & \text { the die and tool cost } \\ C_{r} & \text { rework cost } \\ C_{E C} & \text { carbon emission cost per ton of carbon } \\ E_{c o} & \text { electricity energy consumption } \\ S_{c o} & \text { stem energy consumption } \\ H_{C o} & \text { heating energy consumption } \\ C_{c o} & \text { cooling energy consumption } \\ E_{L R} & \text { loss rate for energy } \\ \varepsilon & \text { indirect emissions factor } \\ a & \text { emissions function parameter for production process (ton.year } 2 / \text { units }^{3} \text { ) } \\ b & \text { emissions function parameter for production process (ton.year/units }{ }^{2} \text { ) } \\ c & \text { emissions function parameter for production process (ton/unit) } \\ v & \text { scaling parameter for setup cost reductions } \\ x(x) & \text { proportion of defective products } \\ B_{v} & \text { expected value of imperfect products } \\ \lambda_{1}, \lambda_{2} & \text { maximum available budget } \\ & \end{array}$

The following assumptions were used to formulate the model:

1. The proposed model studies a two-echelon SC model with a single-vendor and single-buyer setting. The buyer continuously reviews their inventory level and places order a quantity $Q$ as the level of inventory comes to the reorder point. The information about the distribution function for stochastic lead time demand is incomplete, with only the mean and variance known.

2. The production rate is considered as a decision variable to effectively reduce the SC costs, control inventories and tackle demand uncertainties at any stage. 
3. The variable unit production cost directly depends on the optimal production rate $\left(M+\frac{E_{C P}}{P}+\tau P\right)$ and then converges at the optimal production rate.

4. To establish a flexible production system with varying production rates, a vast amount for the setup cost is required. In supply chain models, researchers considered a fixed setup cost for the vendor. However, the setup cost can be reduced by the initial investment to raise the technology of production systems $([3,40])$. For setup cost reductions, a discrete investment function is considered in this study.

5. To make the supply chain model more realistic, inventory storage space, available budget and service level constraints are used. The available space for inventory storage of received final products is always limited at the buyer's place (see references $[28,29]$ ). The budget for production is usually allocated at the start of the process and it is limited to the planned amount. Service level for the customers is crucial for the profitability of the supply chain in general and for the buyer in particular [32].

6. All the products are inspected and imperfect products are separated and sent back for rework. After the rework, these products are considered to have the same quality as perfect products and are directly shipped to the buyer [41].

\section{Mathematical Model}

In this section, the mathematical model for the proposed research problem is formulated. First, the buyer's cost formulations are devised. In the second subsection, authors formulate each cost and total cost for the vendor.

\subsection{Buyer's Mathematical Model}

The first step in the mathematical formulation of the expected total cost for the buyer is to derive the expressions for each cost component for the buyer. Here, the cycle time for the buyer is $Q / D$. The buyer orders a quantity $Q$ to the manufacturer with the ordering cost $A$ per order. Hence, the ordering cost per unit time can be written as " $A D / Q$ ". To keep the lead time in control, the buyer makes some investments $C(L)$ for the reduction of the lead time. Thus, the lead time crashing cost is " $D C(L) / Q$ " per unit time (see the assumption). As the inventory level is reviewed continuously by the buyer, and if the level of inventory drops below or becomes equal to the reorder point $R$, then the buyer places an order of lot size $Q$. The final inventory level for buyer just before reception of the order is " $R-D L$ " and the final inventory level instantaneously after receipt of an order is " $Q+R-D L$ ". Thus, the average inventory level during the cycle for the buyer can be estimated to " $(Q / 2)+R-D L$ ". Hence, the expected holding cost for the buyer per unit time is

$$
\text { Inventory holding cost }=h_{b}\left[\frac{Q}{2}+(R-D L)\right] \text {. }
$$

The leading total expected cost for buyer (per unit time) is therefore given as

$$
\mathrm{TB}_{\mathrm{uyer}}=\frac{A D}{Q}+h_{b}\left[\frac{Q}{2}+(R-D L)^{+}\right]+\frac{D C(L)}{Q} .
$$

This mathematical expression will be used next to obtain the minimum expected cost for the buyer that is subject to a defined fill rate. This service level is considered as the measured fraction of customers' demand that is met regularly and is denoted by

$$
\varphi=\frac{\text { Expected customers' demand met per cycle }}{\text { Expected customers' demand per cycle }},
$$


One can write

$$
\varphi=1-\frac{E(X-R)^{+}}{Q}
$$

and it transforms into

$$
E(X-R)^{+}=(1-\varphi) Q .
$$

We suppose here that $\rho=R-D L$ :

$$
\mathrm{TB}_{\text {uyer }}=\frac{A D}{Q}+h_{b}\left[\frac{Q}{2}+\rho\right]+\frac{D C(L)}{Q} .
$$

In practice, the complete data and information about the lead time demand distribution function are unknown. Hence, researchers are unable to find the exact value of the expected shortages $E(X-R)$ per replenishment cycle. Therefore, authors directly apply the min-max distribution-free approach, as proposed by Scarf [42]. This approach was further simplified and advanced by Gallego and Moon [43] for the inventory problems. Utilizing this method, authors find the distribution function, which is least favorable in $F$ and so minimizes the buyer's annual total cost with regard to the decision variables $(Q$, $L$ ). Therefore, the optimization problem is reduced to:

$$
\operatorname{Min} \operatorname{Max}_{F \in \mathbf{F}} T B_{\text {uyer }}(Q, L, \rho) .
$$

To get the least favorable distribution in F, one can directly use the following lemma

$$
E(X-R)^{+} \leq \frac{1}{2}\left(\sqrt{\sigma^{2} L+\rho^{2}}-\rho\right) ; \text { for any } \mathrm{F} \in \mathbf{F} .
$$

Further, the upper bound for $E(X-R)$ is tight. By taking $\rho_{\varphi}$ as the inventory safety stock with respect to $\varphi$, one can get

$$
(1-\varphi) Q=\frac{\sqrt{\sigma^{2} L+\rho_{\varphi}^{2}}-\rho_{\varphi}}{2},
$$

which transforms to

$$
\rho_{\varphi}=\frac{\sigma^{2} L}{4(1-\varphi) Q}-(1-\varphi) Q .
$$

Furthermore, replacing it in Equation (3), one can get the total expected cost for the buyer as

$$
\mathrm{TB}_{\text {uyer }}=\frac{A D}{Q}+h_{b} Q\left(\varphi-\frac{1}{2}\right)+\frac{h_{b} \sigma^{2} L}{4(1-\varphi) Q}+\frac{D C(L)}{Q} .
$$

In real-world scenarios, the buyer cannot order quantity $Q$ without considering the available warehouse space for the inventory stock. Therefore, it is necessary to consider the space constraint for the buyer to make the mathematical model closer to real life business scenarios. To achieve this, the warehouse space available for the inventory is " $S_{w}$ " and " $s$ " is the space required for a single unit of product. Hence, considering the maximum inventory level instantaneously after receipt of an order is " $Q+R-D L$ ", one can formulate the space constraint as

$$
\left(Q \varphi+\frac{\sigma^{2} L}{4(1-\varphi) Q}\right) s \leq S_{w}
$$

\subsection{Vendor's Mathematical Model}

Now, the total expected cost for the vendor will be calculated, and for this, one needs to calculate each cost component first. The costs of vendor consist of the setup cost, investment for setup cost reduction, inventory holding cost, production cost, inspection cost, reworking cost, and carbon 
emissions cost. This subsection demonstrates the formulation of the expected total cost for the vendor when considering each cost component.

\section{Setup cost}

To produce any product, the vendor needs to make a production setup. For this, the vendor needs an initial setup cost which is generally considered as being fixed. However, there is a possibility to reduce this fixed cost with the extra investment made initially to the production system. The calculated setup cost after the investment can be written as

$$
\text { Setup cost }=\frac{S_{0} e^{-v Z}}{\eta Q}
$$

\section{Investments for setup cost reduction}

The importance of the discrete investments to the production system has been recently proved by many researchers. Accordingly, this model follows the discrete investment policy to reduce the setup cost for the vendor. Thus, the investment made by the vendor for setup cost reduction is

$$
\text { Discrete investment }=\frac{Z D}{Q} \text {. }
$$

\section{Inventory holding cost}

In this model, buyer orders a quantity $Q$ to vendor and the vendor manufactures $s Q$ quantities and ships the $s$ shipment through the single-setup-multi-delivery policy. In practice, there are always chances for the production of imperfect products. Therefore, this model considers that a ratio of produced items is defective. The ratio of defective items cannot be the fixed or predefined for a production system. Therefore, this study considers that the proportion of defective items produced is random with expected value $E(x)$.

$$
\text { Average inventory level }=\frac{Q}{2}\left[\frac{2 D}{(1-E(x)) P}+\eta\left(1-\frac{D}{(1-E(x)) P}\right)-1\right] .
$$

Hence, based on the calculated inventory level, one can formulate the inventory holding cost for the vendor per year as

$$
\text { Holding cost }=\frac{h_{\mathrm{M} Q}}{2}\left[\frac{2 D}{(1-E(x)) P}+\eta\left(1-\frac{D}{(1-E(x)) P}\right)-1\right] .
$$

\section{Production cost}

For the vendor, the main cost to produce products is the production cost. In classical models, the unit production cost has been treated as a fixed cost. However, it can vary with the flexible production rate and reduces with the large production rates. It directly depends on the amount of the produced products.

\section{Inspection cost}

$$
\text { Production cost }=\left(M+\frac{E_{C P}}{P}+\tau P\right) D \text {. }
$$

To make sure only the perfect items are delivered to the buyer and maintain the standard and reputation, the vendor inspects each product before shipping it to the buyer. For the inspection process, a unit inspection $\operatorname{cost} C_{i}$ is charged. Hence, the total inspection cost per year is calculated as

$$
\text { Inspection } \cos \mathrm{t}=C_{i} D \text {. }
$$

\section{Reworking cost}

The inspected items which are classified as imperfect $E(x)$ are sent back to the production setup and reworked to the perfect quality. All the reworked items are considered to be the same as perfect 
quality items. A fixed unit $\operatorname{cost} C_{r}$ is charged to rework these defective items to make them available for a sale with perfect quality. The rework cost for the reworking process per year is calculated as

$$
\text { Reworking cost }=\frac{E(x) P D C_{r}}{Q} .
$$

\section{Carbon emissions cost}

The GHG emissions a vendor produces from industrial work are divided into two major parts: direct emissions and indirect emissions. The manufacturer or vendor has to pay the overall cost of emissions corresponding to the quantity of emissions produced directly or indirectly. The authors are going to calculate these both direct and indirect emissions, respectively.

First, the amount of direct emissions from the production process per unit produced per unit time are calculated as

$$
\text { Carbon emissions during production }=a P^{2}-b P+c \text {. }
$$

Hence, the total amount of emissions produced at the production setup for the demand $D$ per unit time are calculated as

$$
\text { Total carbon emissions during production }=D\left(a P^{2}-b P+c\right) \text {. }
$$

The indirect emissions are produced by the sources which not directly controlled by the vendor. However, these emissions sources are related to the production system. One can calculate the indirect emissions by the electric energy consumptions $E_{c o}(\mathrm{kWh})$, rate of loss of energy $E_{L R}(\%)$, cooling energy consumptions $E_{c o}(\mathrm{kWh})$, heating energy consumptions $H_{e c}(\mathrm{kWh})$ and steam energy consumptions $S_{e c}(\mathrm{kWh})$ to produce a production lot. Hence, one can calculate the indirect carbon emissions for the indirect emission factor $\varepsilon$ (ton per $\mathrm{kWh}$ ) as

$$
\text { Indirect carbon emissions }=\varepsilon\left(E_{c o}+\mathrm{S}_{e c}+H_{e c}+C_{e c}\right) E_{L R} .
$$

Thus, the total amount of indirect carbon emissions per year can be formulated as

$$
\text { Total indirect carbon emissions }=\frac{\varepsilon\left(E_{c o}+\mathrm{S}_{e c}+H_{e c}+C_{e c}\right) E_{L R} D}{\eta Q} .
$$

Thus, one can calculate the final aggregate amount of carbon emissions produced by summation of the direct emissions and indirect emissions.

Total carbon emissions cost $=\left(a P^{2}-b P+c\right) D C_{E C}+\frac{\varepsilon\left(E_{c o}+S_{e c}+H_{e c}+C_{e c}\right) E_{L R} D C_{E C}}{n Q}$.

Accordingly, the expected total cost (per unit time) for the vendor is

$$
\begin{aligned}
\mathrm{TV}_{\text {endor }} & =\frac{S_{0} e^{v Z}}{\eta Q}+\frac{Z D}{Q}+\frac{h_{M} Q}{2}\left[\frac{2 D}{(1-E(x)) P}+\eta\left(1-\frac{D}{(1-E(x)) P}\right)\right] \\
& +\left(M+\frac{E_{C P}}{P}+\tau P\right) D+C_{i} D+\frac{E(x) P D C_{r}}{Q} \\
& +\left(a P^{2}-b P+c\right) D C_{E C}+\frac{\varepsilon\left(E_{c o}+S_{e c}+H_{e c}+C_{e c}\right) E_{L R} D C_{E C}}{\eta Q}
\end{aligned}
$$

A budget constraint is pervasive in vendor-buyer practices, but to the best of the authors' knowledge, an SC model taking into account carbon emissions and a variable production rate has not been described in the literature. Under a stochastic lead time demand and the budget constraint, how to optimally allocate resources to take advantage of variable production rates and also avoid inventory overstock cost is a challenging problem for practitioners. Therefore, this model considers the budget constraints for the vendor to optimize their decisions with reductions in total supply chain 
costs. The available total budget for the production process to the vendor is " $B_{v}$ " and one can formulate the budget constraint for the vendor as

$$
\left(M+\frac{E_{C P}}{P}+\tau P\right) D \leq B_{v} .
$$

Following the formulated costs for the buyer and vendor, one can calculate the total cost for the supply chain as

$$
\begin{aligned}
\mathrm{TC}_{\mathrm{SC}} & =\frac{A D}{Q}+h_{b} Q\left(\varphi-\frac{1}{2}\right)+\frac{h_{b} \sigma^{2} L}{4(1-\varphi) Q}+\frac{D C(L)}{Q}+\frac{S_{0} e^{-v Z}}{\eta Q}+\frac{Z D}{Q}+\left(M+\frac{E_{C P}}{P}+\tau P\right) D \\
& +\frac{h_{M} Q}{2}\left[\frac{2 D}{(1-E(x)) P}+\eta\left(1-\frac{D}{(1-E(x)) P}\right)\right]+C_{i} D+\frac{E(x) P D C_{r}}{Q} \\
& +\left(a P^{2}-b P+c\right) D C_{E C}+\frac{\varepsilon\left(E_{c o}+S_{e c}+H_{e c}+C_{e c}\right) E_{L R} D C_{E C}}{\eta Q} .
\end{aligned}
$$

Subject to the space and budget constraints:

$$
\begin{gathered}
\left(M+\frac{E_{C P}}{P}+\tau P\right) D \leq B_{v} \\
\left(Q \varphi+\frac{\sigma^{2} L}{4(1-\varphi) Q}\right) s \leq S_{w} .
\end{gathered}
$$

\section{Solution methodology}

Optimization with constraints is more complicated than unconstrained optimization and plenty of effort is required to reformulate and solve constrained problems. The most evident method of handling a constraint is to convert a constrained optimization problem into a new unconstrained optimization problem [44]. This conversion can sometimes be done in a way in which the original constraints cannot be violated in the transformed problem. The method of Lagrange multipliers converts a constrained optimization problem into an unconstrained one [45]. As such, this model is a highly non-linear and constraint problem, thus the Khun-Tucker methodology is the most effective approach to determine the global optimum solution [29,46,47]. Foundation provided by the Khun-Tucker methodology; the Lagrangian multiplier approach is utilized for converting the proposed constrained problem to an unconstrained problem. Considering the Lagrangian multiplier, one can write

$$
\begin{aligned}
\mathrm{TC}_{\mathrm{SC}}\left(Q, P, Z, L, \eta, \lambda_{1}, \lambda_{2}\right) & =\frac{A D}{Q}+h_{b} Q\left(\varphi-\frac{1}{2}\right)+\frac{h_{b} \sigma^{2} L}{4(1-\varphi) Q}+\frac{D C(L)}{Q}+\frac{S_{0} e^{-v Z}}{\eta Q}+\frac{Z D}{Q}+C_{i} D \\
& +\left(M+\frac{E_{C P}}{P}+\tau P\right) D+\frac{h_{M} Q}{2}\left[\frac{2 D}{(1-E(x)) P}+\eta\left(1-\frac{D}{(1-E(x)) P}\right)\right] \\
& +\frac{E(x) P D C_{r}}{Q}+\left(a P^{2}-b P+c\right) D C_{E C}+\frac{\varepsilon\left(E_{c o}+S_{e c}+H_{e c}+C_{e c}\right) E_{L R} D C_{E C}}{\eta Q} \\
& +\lambda_{1}\left(\left(M+\frac{E_{C P}}{P}+\tau P\right) D-B_{v}\right)+\lambda_{2}\left(\left(Q \varphi+\frac{\sigma^{2} L}{4(1-\varphi) Q}\right) s-S_{w}\right) .
\end{aligned}
$$

To find the necessary conditions for the minimum cost of $T C_{S C}(\#)$ one must calculate the partial derivatives of the cost function (replace $\operatorname{TC}_{\mathrm{SC}}\left(Q, P, Z, L, \eta, \lambda_{1}, \lambda_{2}\right)=\mathrm{TC}_{\mathrm{SC}}(\#)$ ).

$$
\begin{aligned}
\frac{\partial \mathrm{TC}_{S C}(\#)}{\partial Q}= & -\frac{A D}{Q^{2}}+h_{b}\left(\varphi-\frac{1}{2}\right)-\frac{h_{b} \sigma^{2} L}{4(1-\varphi) Q^{2}}-\frac{D C(L)}{Q^{2}}-\frac{S_{0} e^{-v Z}}{\eta Q^{2}}-\frac{Z D}{Q^{2}} \\
& +\frac{h_{M}}{2}\left[\frac{2 D}{(1-E(x)) P}+\eta\left(1-\frac{D}{(1-E(x)) P}\right)\right]-\frac{E(x) P D C_{r}}{Q^{2}} \\
& -\frac{\varepsilon\left(E_{c o}+S_{e c}+H_{e c}+C_{e c}\right) E_{L R} D C_{E C}}{\eta Q^{2}}+\lambda_{2}\left(\varphi-\frac{\sigma^{2} L}{4(1-\varphi) Q^{2}}\right) s, \\
\frac{\partial \mathrm{TC}_{S C}(\#)}{\partial P}= & \left(-\frac{E_{C P}}{P^{2}}+\tau\right) D+\frac{h_{M} Q}{2}\left[-\frac{2 D}{(1-E(x)) P^{2}}-\frac{\eta D}{(1-E(x)) P^{2}}\right]+\frac{E(x) D C_{r}}{Q} \\
+ & (2 a P-b) D C_{E C}+\lambda_{1}\left(-\frac{E_{C P}}{P^{2}}+\tau\right) D,
\end{aligned}
$$




$$
\begin{aligned}
& \frac{\partial \mathrm{TC}_{\mathrm{SC}}(\#)}{\partial Z}=-\frac{v \log (e) S_{0} e^{-v Z}}{\eta Q}+\frac{D}{Q^{\prime}} \\
& \frac{\partial \mathrm{TC}_{\mathrm{SC}}(\#)}{\partial L}=\frac{h_{b} \sigma^{2}}{4(1-\varphi) Q}-\frac{D}{Q}+\lambda_{2}\left(\frac{\sigma^{2}}{4(1-\varphi) Q}\right) s, \\
& \frac{\partial \mathrm{TC}_{\mathrm{SC}}(\#)}{\partial \eta}=-\frac{S_{0} e^{-v Z}}{\eta^{2} Q}+\frac{h_{M} Q}{2}\left(1-\frac{D}{(1-E(x)) P}\right)-\frac{\varepsilon\left(E_{c o}+S_{e c}+H_{e c}+C_{e c}\right) E_{L R} D C_{E C}}{\eta^{2} Q}, \\
& \frac{\partial \mathrm{TC}_{\mathrm{SC}}(\#)}{\partial \lambda_{1}}=\left(M+\frac{E_{C P}}{P}+\tau P\right) D-B_{v}, \\
& \frac{\partial \mathrm{TC}_{\mathrm{SC}}(\#)}{\partial \lambda_{2}}=\left(Q \varphi+\frac{\sigma^{2} L}{4(1-\varphi) Q}\right) s-S_{w} .
\end{aligned}
$$

The necessary conditions for decision variables to be global optimal are that the partial derivatives of $T C_{S C}(\#)$ are equal to zero for each variable. The cost $T C_{S C}(\#)$ achieves the global minimum only if the second derivatives are positive for the decision variables. As assumed in the model, the value for the shipments $\eta$ must be a positive integer; the derivatives are therefore not considered. However,

$$
\begin{gathered}
\frac{\partial^{2} \mathrm{TC}_{S C}(\#)}{\partial Q^{2}}=\frac{2 A D}{Q^{3}}+\frac{h_{b} \sigma^{2} L}{2(1-\varphi) Q^{3}}+\frac{2 D C(L)}{Q^{3}}+\frac{2 S_{0} e^{-v Z}}{\eta Q^{3}}+\frac{2 Z D}{\eta Q^{3}}++\frac{2 E(x) P D C_{r}}{Q^{3}} \\
+\frac{2 \varepsilon\left(E_{c o}+S_{e c}+H_{e c}+C_{c c}\right) E_{L R} D C_{E C}}{\eta Q^{3}}+\lambda_{2}\left(\frac{\sigma^{2} L}{2(1-\varphi) Q^{3}}\right) s, \\
\frac{\partial^{2} \mathrm{TC}_{S C}(\#)}{\partial P^{2}}=\frac{2 E_{C P}}{P^{3}} D+\frac{h_{M} Q}{2}\left[\frac{4 D}{(1-E(x)) P^{3}}+\frac{2 \eta D}{(1-E(x)) P^{3}}\right]+(2 a) D C_{E C}+\lambda_{1}\left(\frac{2 E_{C P}}{P^{3}}\right) D, \\
\frac{\partial^{2} \mathrm{TC}_{S C}(\#)}{\partial Z^{2}}=\frac{v^{2} \log ^{2}(e) S_{0} e^{-v Z}}{\eta Q}, \\
\frac{\partial \mathrm{TC}_{S C}(\#)}{\partial L}=0, \\
\frac{\partial \mathrm{TC}_{\mathrm{SC}}(\#)}{\partial \eta}=\frac{2 S_{0} e^{-v Z}}{\eta^{3} Q}+\frac{2 \varepsilon\left(E_{c o}+S_{e c}+H_{e c}+C_{e c}\right) E_{L R} D C_{E C}}{\eta^{3} Q} .
\end{gathered}
$$

One can calculate the optimal $Q$ and $P$ from the necessary conditions defined above.

$$
\begin{gathered}
Q=\sqrt{\frac{A D+\frac{S_{0} e^{-v Z} D}{\eta}+Z D+\frac{h_{b} \sigma^{2} L}{4(1-\varphi)}+\frac{\lambda_{2} \sigma^{2} L s}{4(1-\varphi)}+-\frac{\varepsilon\left(E_{c o}+S_{e c}+H_{e c}+C_{c c} E_{L R} D C_{E C}\right.}{\eta}}{h_{b}\left(\theta-\frac{1}{2}\right)+\frac{h_{M}}{2}\left[\frac{2 D}{(1-E(x)) P}+\eta\left(1-\frac{D}{(1-E(x)) P}\right)\right]+\lambda_{2} \varphi s}}, \\
\frac{1}{P^{2}}=\frac{\tau D+\frac{E(x) D C_{r}}{Q}+(2 a P-b) D C_{E C}+\lambda_{1} \tau D}{E_{C P}+\lambda_{1} E_{C P} D+\frac{h_{M} Q}{2}\left[\frac{2 D}{(1-E(x))} \frac{\eta D}{(1-E(x))}\right]} .
\end{gathered}
$$

and

$$
\rho_{\varphi}=\frac{\sigma^{2} L}{4(1-\varphi) Q}-(1-\varphi) Q .
$$

Propositions. The $T C_{S C}(\#)$ has the global minimum value at $Q^{*}, P^{*}$ and $Z^{*}$ if all the principal minors satisfy $H i j>0$. 
Proof. By using the formulation of the Hessian Matrix, one can prove that the $T C_{S C}(\#)$ has attained the global minimum. The Hessian Matrix can be given as

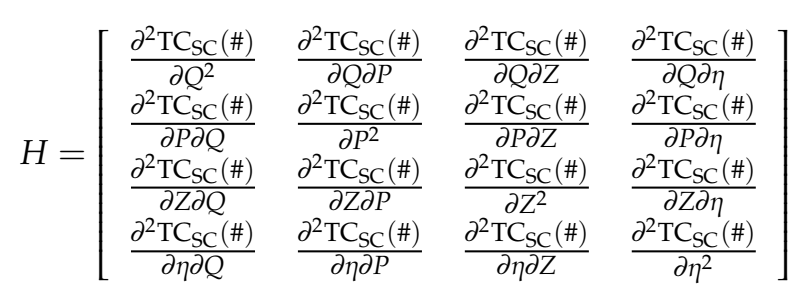

Since the developed system of equations for the $T C_{S C}(\#)$ is a complex non-linear function, it is therefore difficult to prove optimality analytically. Therefore, the proof of the Hessian Matrix can be seen in next section with using optimal values.

According to the Kuhn-Tucker (KT) conditions: the first of the KT conditions is

$$
\begin{aligned}
& \frac{\partial \operatorname{TC}_{S C}(Q, P, Z, \eta)}{\partial Q} \geq 0 \\
& \frac{\partial \operatorname{TC}_{S C}(Q, P, Z, \eta)}{\partial P} \geq 0 \\
& \frac{\partial \operatorname{TC}_{S C}(Q, P, Z, \eta)}{\partial Z} \geq 0 \\
& \frac{\partial \operatorname{TC}_{S C}(Q, P, Z, \eta)}{\partial \eta} \geq 0
\end{aligned}
$$

The second of the KT conditions is

$$
\begin{aligned}
& Q\left(\frac{\partial \mathrm{TC}_{\mathrm{SC}}(Q, P, Z, \eta)}{\partial Q}\right) \geq 0, \\
& P\left(\frac{\partial \mathrm{TC}_{\mathrm{SC}}(Q, P, Z, \eta)}{\partial P}\right) \geq 0, \\
& Z\left(\frac{\partial \mathrm{TC}_{\mathrm{SC}}(Q, P, Z, \eta)}{\partial Z}\right) \geq 0, \\
& \eta\left(\frac{\partial \mathrm{TC}_{\mathrm{SC}}(Q, P, Z, \eta)}{\partial \eta}\right) \geq 0 .
\end{aligned}
$$

The third of the KT conditions is

$$
\left(M+\frac{E_{C P}}{P}+\tau P\right) D-B_{v} \leq 0,\left(Q \varphi+\frac{\sigma^{2} L}{4(1-\varphi) Q}\right) s-S_{w} \leq 0 .
$$

Finally, the final fourth of the KT conditions is

$$
\lambda_{1}\left[\left(M+\frac{E_{C P}}{P}+\tau P\right) D-B_{v}\right]=0, \lambda_{1}\left[\left(Q \varphi+\frac{\sigma^{2} L}{4(1-\varphi) Q}\right) s-S_{w}\right]=0 .
$$

\section{Numerical example}

In this section, the authors conduct numerical experiments to verify the provided theoretical analysis of the proposed model, and managerial insights are provided.

The input data for the Example 1 is given in Table 2 to analyze the mathematical model for the industrial problems (this data is taken from the literature). The authors analyzed the proposed model for the centralized decision making and decentralized decision making based on the given data and tried to draw important insights from the results with the help of different graphs and tables. 
Table 2. Input parameters for Example 1.

\begin{tabular}{cccc}
\hline$D=400$ & $S_{0}=1000$ & $h_{M}=6$ & $h_{b}=10$ \\
\hline$\sigma=7$ & $A=200$ & $C_{E C}=20$ & $C_{m}=15$ \\
$\nu=0.01$ & $E_{C P}=2000$ & $\tau=0.003$ & $C_{i}=2$ \\
$C_{r}=2$ & $a=0.0000003$ & $b=0.0012$ & $c=1.4$ \\
$\alpha=5 \%$ & $\beta=15 \%$ & $\varepsilon=0.02264$ & $E_{c o}=6182.24$ \\
$S_{e c}=4636.68$ & $H_{e c}=1545.56$ & $C_{e c}=3091.12$ & $E_{L R}=0.01$ \\
$B_{v}=10,000$ & $S_{w}=3000$ & $s=5$ & $\theta=0.95$ \\
\hline
\end{tabular}

The results for the Example 1 are given in Table 3. One can see the obtained optimal values for the decision variables $\left(Q^{*}, P^{*}, Z^{*}, L^{*}, \eta^{*}\right)$ and the cost of the SC under both centralized and decentralized SC settings. By looking at Table 3 , one will observe that the value of the total cost for SC is significantly lower under the centralized SC than under the decentralized SC. In general, centralized or integrated SC models perform economically and environmentally better than the decentralized SC models.

Table 3. The optimal results for Example 1.

\begin{tabular}{ccccccccc}
\hline & $Q^{*}$ & $P^{*}$ & $Z^{*}$ & $\eta^{*}$ & $L^{*}$ & $T V_{\text {endor }}$ & $\mathbf{T B}_{\text {uyer }}$ & Total Cost \\
\hline Integrated Model & 295.8 & 1772.8 & 230 & 1 & 4 & - & - & $14,209.4$ \\
Decentralized Model & 187.1 & 1733.7 & 230 & 1 & 4 & $12,852.8$ & 1684.1 & $14,536.9$ \\
\hline
\end{tabular}

The generated Hessian matrix can be given as below. Moreover, the given Hessian matrix at optimal values of all the decision variables is a positive definite, given as,

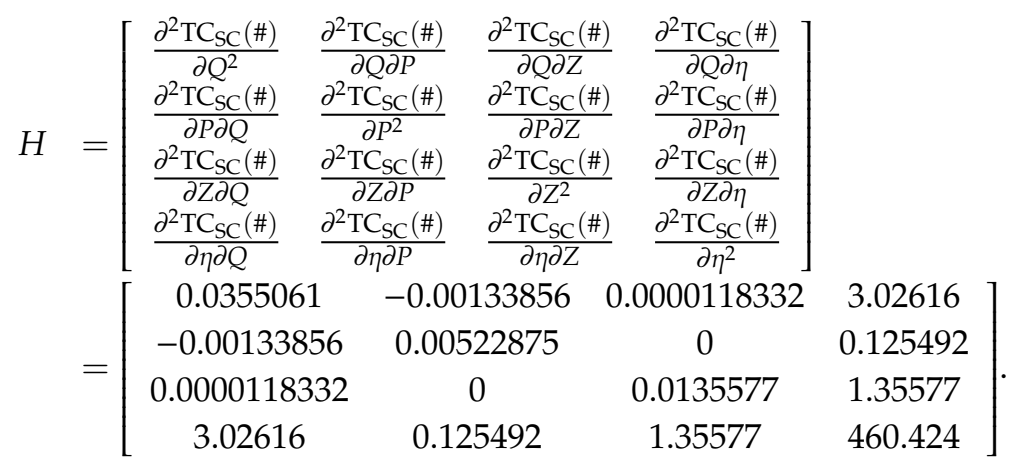

Also, all eigenvalues $(460.448,0.0221317,0.00593374,0.00231065)$ of the Hessian matrix are positive.

The input data for the example 2 is given in Table 4 (taken from the literature [48] and [16]) and the optimal results $\left(Q^{*}, P^{*}, Z^{*}, L^{*}, \eta^{*}\right)$ obtained from the model are given in Table 5. Similar to in Example 1, the results of the Example 2 show a lower cost under the centralized or integrated model than under the decentralized model. These results in Tables 3 and 5 show that the coordination policy in terms of centralized decisions and decentralized decision greatly impact the total cost of the SC systems. Hence, the economic performance of the centralized or integrated SC system is higher than the decentralized SC systems with regards to the total cost of the SC. In the next few paragraphs, the authors analyze the environmental performance of the proposed model under centralized and decentralized decision policies.

Figure 1 presents the graphical illustration of the total SC cost with the varying $Q$ and $P$. From the figure, it is clear that the total SC cost is at its minimum at the optimal $Q$ and P. Hence, the obtained global optimal values are the correct ones. Figure 2 represents the amount of carbon emissions against the varying $Q$ and $P$. From Figure 2, it can be noted that the amount of emissions is lower at the optimal values of both $Q$ and $P$ as well. Hence, the obtained values of $Q$ and $P$ are optimal in terms of both the SC cost and the amount of emissions. Therefore, this proposed model presents a strong point to follow 
the flexible production system with variable production rates along with the optimal order quantity and investments to reduce the setup cost and lead time.

Table 4. Input parameters for Example 2.

\begin{tabular}{cccc}
\hline$D=600$ & $S_{0}=1500$ & $h_{M}=14$ & $h_{b}=20$ \\
$\sigma=7$ & $A=200$ & $C_{E C}=20$ & $C_{m}=15$ \\
$v=0.01$ & $B=2500$ & $\tau=0.003$ & $C_{i}=2$ \\
$C_{r}=2$ & $a=0.0000003$ & $b=0.0012$ & $c=1.4$ \\
$\alpha=5 \%$ & $\beta=15 \%$ & $\varepsilon=0.02264$ & $E_{c o}=6182.24$ \\
$S_{e c}=4636.68$ & $H_{e c}=1545.56$ & $C_{e c}=3091.12$ & $E_{R L}=0.01$ \\
$B_{v}=20,000$ & $S_{w}=3000$ & $s=5$ & $\theta=0.95$ \\
\hline
\end{tabular}

Table 5. The optimal results for Example 2.

\begin{tabular}{ccccccccc}
\hline & $Q^{*}$ & $P^{*}$ & $Z^{*}$ & $\eta^{*}$ & $L^{*}$ & $T_{\text {endor }}$ & TB $_{\text {uyer }}$ & Total Cost \\
\hline Integrated Model & 196.9 & 1285.4 & 50 & 1 & 3 & - & - & $28,291.4$ \\
\hline Decentralized Model & 169.1 & 1266.4 & 50 & 1 & 3 & $25,303.7$ & 3043.7 & $28,347.4$ \\
\hline
\end{tabular}

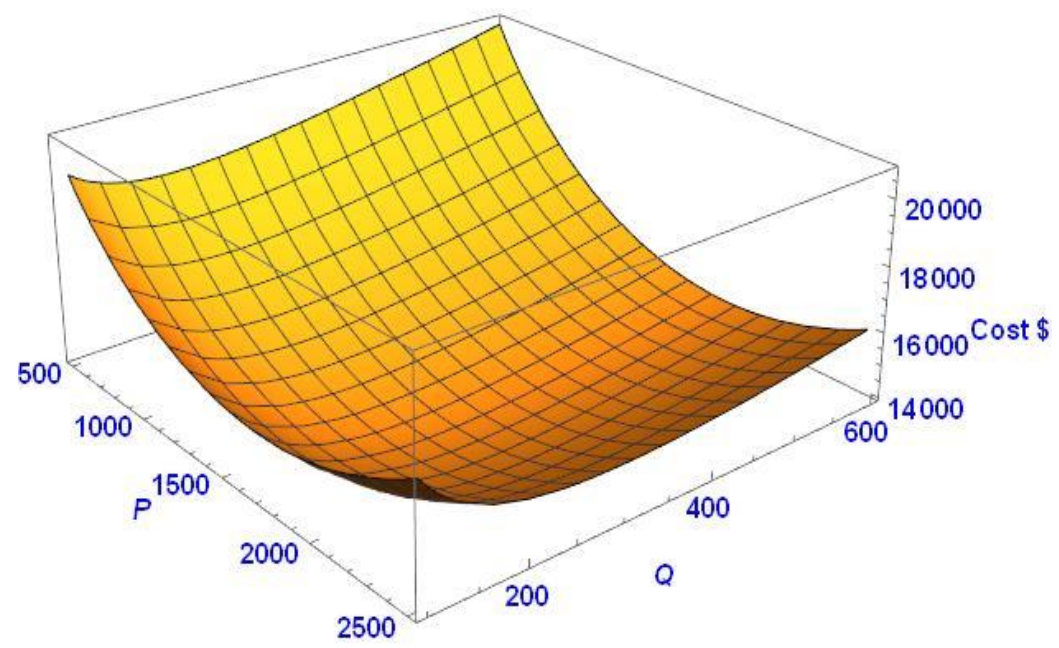

Figure 1. Total supply chain cost versus the $Q$ and $P$.

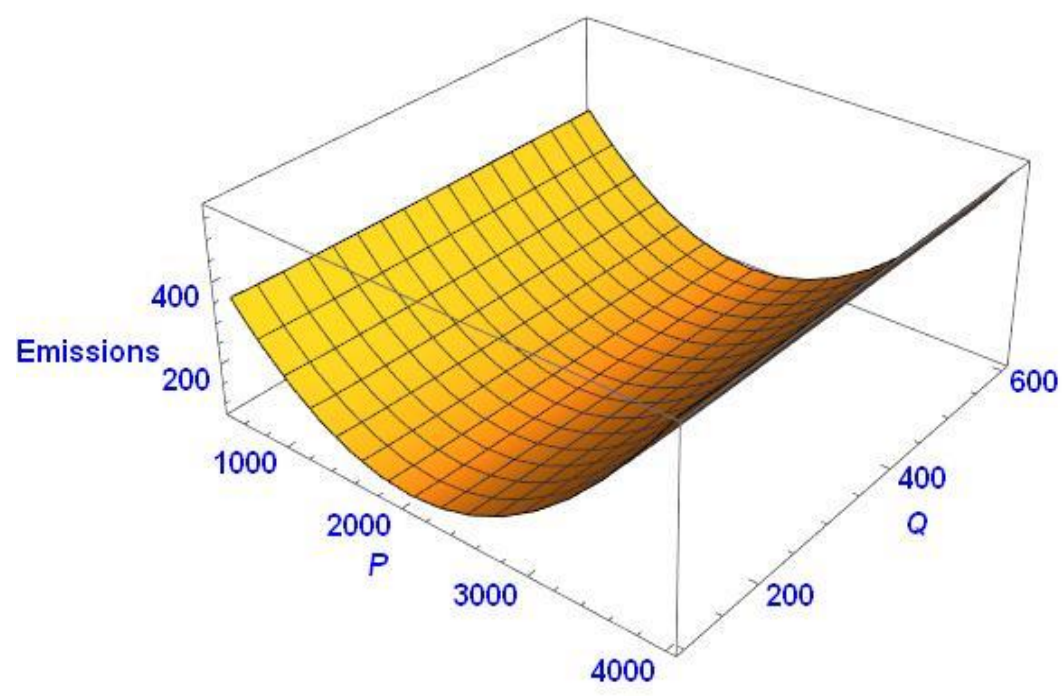

Figure 2. Amount of emissions versus the $Q$ and $P$. 
The graph in Figure 3 illustrates the amount of emissions with varying production rate $P$. The amount of emissions is at its minimum at the obtained optimal value of the $P$ in the proposed model under the centralized decision-making model. The amount of emissions at lower or higher values of $P$ is more as compared to the optimal value. Therefore, one should use this model for better environmental performance of the production system. In Figure 4, it is evident that the amount of carbon emissions at the optimal value of $P$ under the centralized decision-making model is lower than under the decentralized decision-making model. Hence, the integrated or centralized decision making is performing significantly better as compared to the decentralized decision-making in both the environment and economics aspects of the SC model.

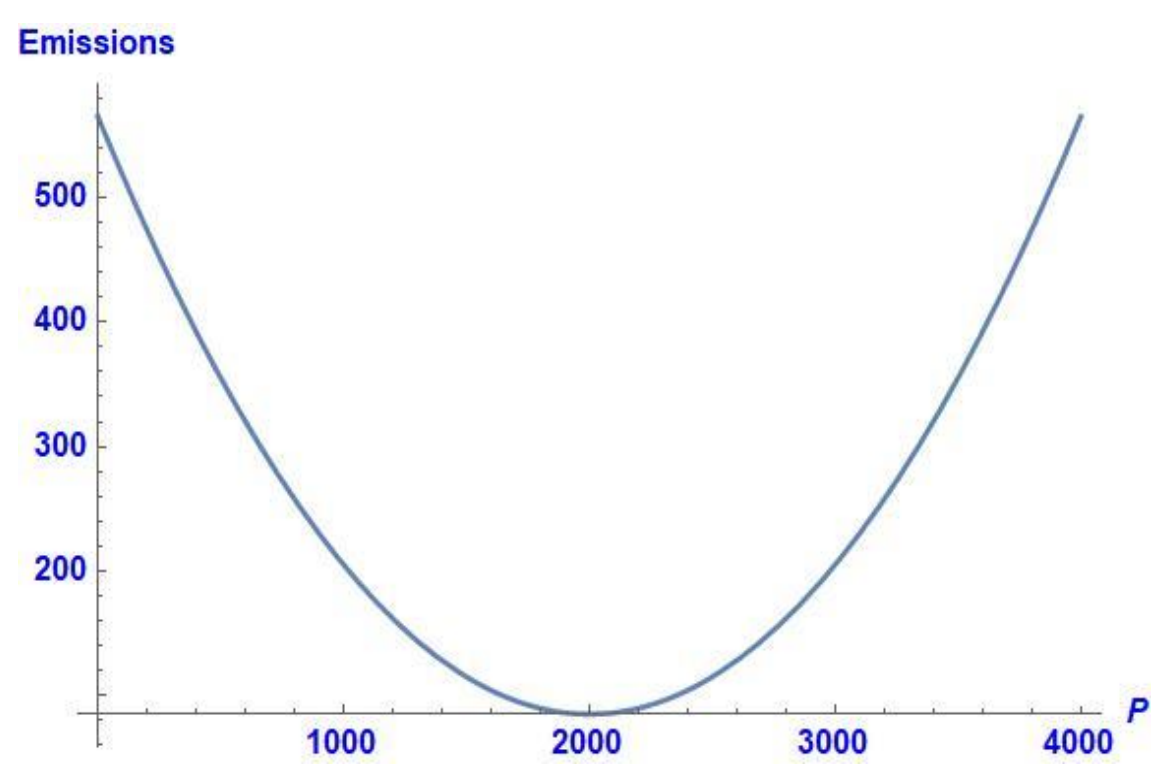

Figure 3. Change in total emission versus the $P$.

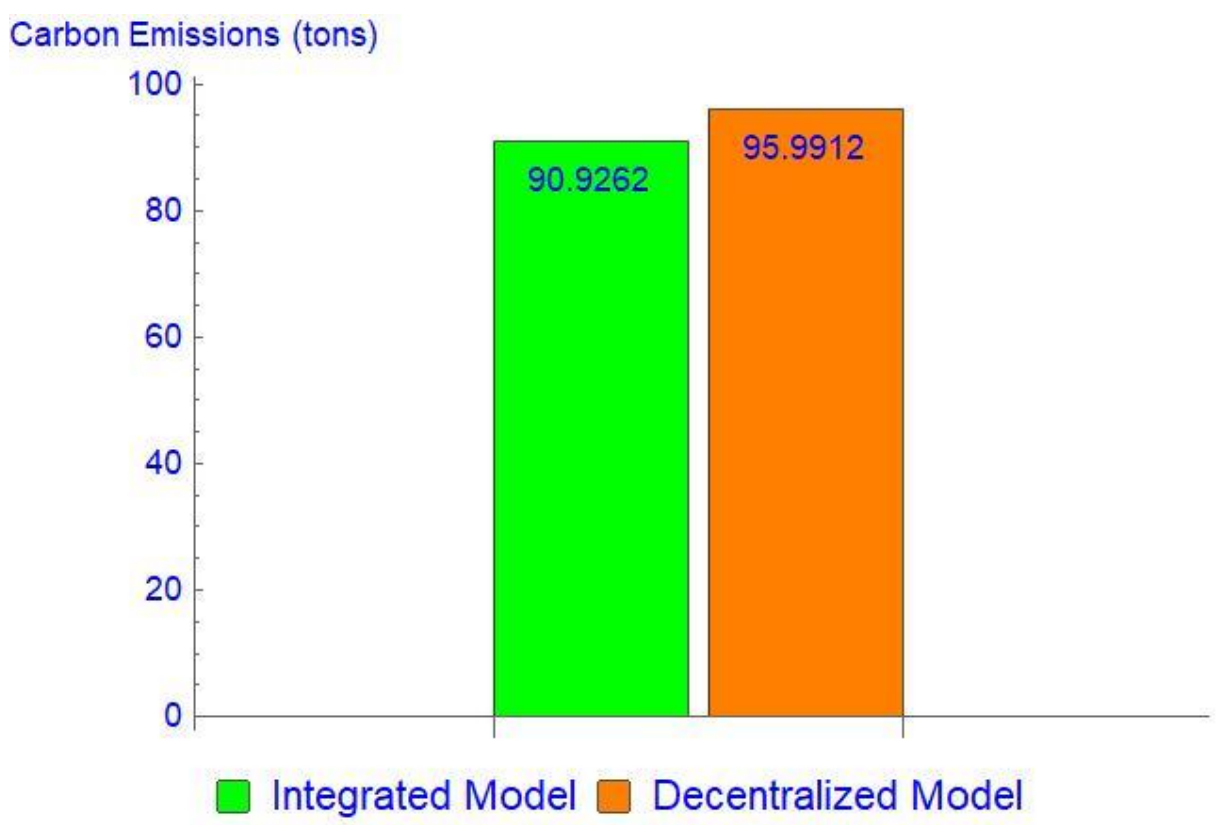

Figure 4. Comparison of amount of carbon emission under the integrated model and a decentralized model. 
The obtained optimal results of the proposed SC model are further assessed for the potential variations in some key parameters of Example 1 under the integrated model. The impact of these key parameters on the optimal SC cost is summarized in Table 6 . The values of parameters are $-50 \%$, $-25 \%,+25 \%$ and $+50 \%$ :

i. It is evident from Table 6 that the material cost is the most sensitive parameter for the SC cost. The positive or the negative change in parameter value has the same impact on the cost function. For example, the $-25 \%$ change in parametric value causes a decrease of $10.6899 \%$ to the total cost, and the value increases by $10.6899 \%$ with the $+25 \%$ parametric value.

ii. The carbon emission cost is the second most sensitive parameter in the proposed model, with an almost $7 \%$ decrease in SC cost as well as a $50 \%$ decrease in the value. The impact of reduction in emission costs is slightly higher than the increase in the value. Therefore, the amount of emissions produced during the production process plays a crucial role in economic performance as well as the environmental performance of the SC model.

iii. The holding cost for the buyer is another parameter that is greatly sensitive to the SC cost. In fact, this model considered the single-setup multi-delivery policy for the buyer's holding cost sensitivity to reduce the SC cost. It helps the managers to control the holding cost at the buyer's end by replenishing the order quantity in multiple deliveries.

iv. The parameters like inspection cost, reworking cost, energy cost and scaling parameter for setup cost reduction are moderately sensitive to the SC cost. In contrast, the ordering cost, initial setup cost and the holding cost for the vendor are lightly sensitive to the SC cost.

The numerical and sensitivity analysis provides essential insights for the SC management to formulate optimal decision policies that can attain the best outcomes based on economic and environmental performances. For the manufacturing industry, the most important factor is the production rate. The production rate is considered as a variable, and it requires a realistic approach rather than fixed production rates. The managers can utilize the variable production rate to control the holding cost by adjusting the number of items produced according to the demands and reduce the number of imperfect items. In fact, the SC cost can be reduced. In addition, the vendor is using a flexible production system, meaning an increase in setup cost may occur. Therefore, an investment is required to control the setup cost and keep the total SC cost to the minimum level. The significant benefit is that the vendor uses a discrete investment, and it can be utilized when required and stopped at any time. The lead time investments are made to reduce the lead time and hence can improve the service level, which plays a critical role in the profitability of the SC models. From the results, it is evident that the carbon emissions at the optimal values of decision variables are smaller for the integrated model than for the decentralized model. The relevant managers should adopt an integrated decision policy or make other possible coordination mechanisms to reduce and control the amount of emissions.

For any industry in this competitive business environment, production setup flexibility with variable production rates plays a crucial role. By applying the variable production rate, industry managers can significantly reduce the number of imperfect items and control the number of produced items to reduce their holding costs. Hence, this will help to cut down the supply chain costs. For environmental performance, a flexible production setup provides an opportunity for production planners to reduce carbon emissions by optimizing their variable production rates. Accordingly, they can increase or reduce the speed of production of finished products to control and reduce carbon emissions. Additionally, the discrete investments made for the setup cost reductions also helps managers to minimize setup costs required for each production cycle. Further, the discrete investment policy provides flexibility in terms of making investments when needed, and to stop investing when the funds are not available or the setup cost reduction per $\$$ spent is small. 
Table 6. Sensitivity analysis for the total SC cost (The Integrated SC for Example 1).

\begin{tabular}{|c|c|c|c|c|c|}
\hline Parameter(s) & $\%$ Change & $\begin{array}{c}\% \text { Change in } \\
T C_{S C}(\#)\end{array}$ & Parameter(s) & $\%$ Change & $\begin{array}{c}\% \text { Change in } \\
T C_{S C}(\#)\end{array}$ \\
\hline \multirow{4}{*}{$S_{0}$} & -50 & -0.2558 & \multirow{4}{*}{$C_{E C}$} & -50 & -6.9235 \\
\hline & -25 & -0.1276 & & -25 & -3.3309 \\
\hline & +25 & +0.1268 & & +25 & +3.2141 \\
\hline & +50 & +0.2529 & & +50 & +6.3662 \\
\hline \multirow{4}{*}{$A$} & -50 & -1.0490 & \multirow{4}{*}{$C_{r}$} & -50 & -1.9042 \\
\hline & -25 & -0.5174 & & -25 & -0.9265 \\
\hline & +25 & +0.5053 & & +25 & +0.8837 \\
\hline & +50 & +0.9992 & & +50 & +1.7296 \\
\hline \multirow{4}{*}{$h_{b}$} & -50 & -5.1924 & \multirow{4}{*}{$C_{i}$} & -50 & -2.8506 \\
\hline & -25 & -2.4259 & & -25 & -1.4253 \\
\hline & +25 & +2.1943 & & +25 & +1.4253 \\
\hline & +50 & +4.2176 & & +50 & +2.8506 \\
\hline \multirow{4}{*}{$h_{M}$} & -50 & -0.7639 & \multirow{4}{*}{$M$} & -50 & -21.3798 \\
\hline & -25 & -0.3777 & & -25 & -10.6899 \\
\hline & +25 & +0.3713 & & +25 & +10.6899 \\
\hline & +50 & +0.7347 & & +50 & +21.3798 \\
\hline \multirow{4}{*}{$E_{C P}$} & -50 & -1.6234 & \multirow{4}{*}{$N$} & -50 & +1.7033 \\
\hline & -25 & -0.8089 & & -25 & +0.5616 \\
\hline & +25 & +0.8032 & & +25 & -0.2701 \\
\hline & +50 & +1.6014 & & +50 & -0.3991 \\
\hline
\end{tabular}

\section{Conclusions and Future Research}

The variable production rate, along with three real-life based constraints and carbon emissions, was introduced within an SC model to minimize the total cost and reduce the number of defective items in the production process. In contrast to the existing literature, the production rate was studied as a decision variable, and a random number of defective items was utilized to make the production process more flexible. Besides, the lead time was reduced with the help of extra costs, and a discrete investment was made to control the setup cost. The goal of SC was to minimize the total cost by obtaining the optimal values of the decision variables. The classical Kuhn-Tucker (KT) optimization technique was utilized to get the solutions for the proposed constrained problem. Numerical examples showed that this proposed model attained its global minimum SC cost at the optimum values of all the decision variables.

This study is made-up to support flexible production, where the imperfections happen during the production process. It introduces the budget, space and service level constraints with the consideration of imperfect items as being random, as well as carbon emissions during the production process. Thus, the novelty of this study is the introduction of real-life constraints with direct and indirect carbon emissions along with the random defective rate. The numerical experiments comprising of two examples are conducted and further analyzed through sensitivity analysis. Analysis of the study illustrates the significant advantage of this model by highlighting the importance of the investments to the setup cost and lead time reduction, as the results suggest that the flexible production rate helps managers to reduce the amount of emissions and the holding cost for the vendor. Hence, it enhances the economic and environmental performance of the SC model.

Despite these various benefits, the current study has limitations as well. It has considered fixed demand, whereas it is quite natural that the demand is uncertain and cannot be predicted with complete accuracy. Besides, the reworking process has been considered as being perfect. However, imperfections may develop during the reworking phase at the production setup. The analysis indicates that the carbon emission cost is among the most sensitive parameters in SC. However, this study has not provided the emission reduction strategy needed to minimize the cost and environmental 
impact of the production process. In addition, this model can be extended with multiple buyers [8], multi-stage production [34], price discounts [31], different coordination schemes [23,48] and different rework options.

Author Contributions: Conceptualization, A.I.M.; Methodology, A.I.M.; Software, A.I.M.; Validation, B.S.K.; Formal analysis, A.I.M.; Investigation, B.S.K. and A.I.M.; Resources, B.S.K.; Data curation, A.I.M.; Writing-original draft preparation, A.I.M.; Writing-review and editing, B.S.K.; Visualization, A.I.M.; Supervision, B.S.K. All authors have read and agreed to the published version of the manuscript.

Funding: This work was supported by Research Assistance Program (2019) in the Incheon National University.

Conflicts of Interest: The authors declare no conflicts of interest.

\section{References}

1. Moussa, F.Z.B.; Rasovska, I.; Dubois, S.; De Guio, R.; Benmoussa, R. Reviewing the use of the theory of inventive problem solving (TRIZ) in green supply chain problems. J. Clean. Prod. 2017, 142, 2677-2692. [CrossRef]

2. Glock, C.H. A comment: “Integrated single vendor-single buyer model with stochastic demand and variable lead time". Int. J. Prod. Econ. 2009, 122, 790-792. [CrossRef]

3. Sarkar, M.; Chung, B.D. Flexible work-in-process production system in supply chain management under quality improvement. Int. J. Prod. Res. 2019, 1-18. [CrossRef]

4. Khouja, M.; Mehrez, A. Economic production lot size model with variable production rate and imperfect quality. J. Oper. Res. Soc. 1994, 45, 1405-1417. [CrossRef]

5. Glock, C.H. Batch sizing with controllable production rates. Int. J. Prod. Res. 2010, 48, 5925-5942. [CrossRef]

6. Glock, C.H. Batch sizing with controllable production rates in a multi-stage production system. Int. J. Prod. Res. 2011, 49, 6017-6039. [CrossRef]

7. AlDurgam, M.; Adegbola, K.; Glock, C.H. A single-vendor single-manufacturer integrated inventory model with stochastic demand and variable production rate. Int. J. Prod. Econ. 2017, 191, 335-350. [CrossRef]

8. Sarkar, B.; Majumder, A.; Sarkar, M.; Kim, N.; Ullah, M. Effects of variable production rate on quality of products in a single-vendor multi-buyer supply chain management. Int. J. Adv. Manuf. Technol. 2018, 99, 567-581. [CrossRef]

9. Dey, B.K.; Sarkar, B.; Pareek, S. A two-echelon supply chain management with setup time and cost reduction, quality improvement and variable production rate. Mathematics 2019, 7, 328. [CrossRef]

10. Majumder, A.; Jaggi, C.K.; Sarkar, B. A multi-retailer supply chain model with backorder and variable production cost. RAIRO-Oper. Res. 2018, 52, 943-954. [CrossRef]

11. Sarkar, M.; Kim, S.; Jemai, J.; Ganguly, B.; Sarkar, B. An application of time-dependent holding costs and system reliability in a multi-item sustainable economic energy efficient reliable manufacturing system. Energies 2019, 12, 2857. [CrossRef]

12. Dehning, P.; Blume, S.; Dér, A.; Flick, D.; Herrmann, C.; Thiede, S. Load profile analysis for reducing energy demands of production systems in non-production times. Appl. Energy 2019, 237, 117-130. [CrossRef]

13. Biel, K.; Glock, C.H. Systematic literature review of decision support models for energy-efficient production planning. Comput. Ind. Eng. 2016, 101, 243-259. [CrossRef]

14. Marchi, B.; Zanoni, S. Supply chain management for improved energy efficiency: Review and opportunities. Energies 2017, 10, 1618. [CrossRef]

15. Marchi, B.; Zanoni, S.; Ferretti, I.; Zavanella, L.E. Stimulating investments in energy efficiency through supply chain integration. Energies 2018, 11, 858. [CrossRef]

16. Wangsa, I. Greenhouse gas penalty and incentive policies for a joint economic lot size model with industrial and transport emissions. Int. J. Ind. Eng. Comput. 2017, 8, 453-480.

17. Wahab, M.; Mamun, S.; Ongkunaruk, P. EOQ models for a coordinated two-level international supply chain considering imperfect items and environmental impact. Int. J. Prod. Econ. 2011, 134, 151-158. [CrossRef]

18. Hua, G.; Cheng, T.; Wang, S. Managing carbon footprints in inventory management. Int. J. Prod. Econ. 2011, 132, 178-185. [CrossRef]

19. Benjaafar, S.; Li, Y.; Daskin, M. Carbon footprint and the management of supply chains: Insights from simple models. IEEE Trans. Autom. Sci. Eng. 2012, 10, 99-116. [CrossRef] 
20. Chen, X.; Benjaafar, S.; Elomri, A. The carbon-constrained EOQ. Oper. Res. Lett. 2013, 41, 172-179. [CrossRef]

21. Jaber, M.Y.; Glock, C.H.; El Saadany, A.M. Supply chain coordination with emissions reduction incentives. Int. J. Prod. Res. 2013, 51, 69-82. [CrossRef]

22. Bazan, E.; Jaber, M.Y.; Zanoni, S. Supply chain models with greenhouse gases emissions, energy usage and different coordination decisions. Appl. Math. Model. 2015, 39, 5131-5151. [CrossRef]

23. Bazan, E.; Jaber, M.Y.; Zanoni, S. Carbon emissions and energy effects on a two-level manufacturer-retailer closed-loop supply chain model with remanufacturing subject to different coordination mechanisms. Int. J. Prod. Econ. 2017, 183, 394-408. [CrossRef]

24. Micheli, G.J.; Mantella, F. Modelling an environmentally-extended inventory routing problem with demand uncertainty and a heterogeneous fleet under carbon control policies. Int. J. Prod. Econ. 2018, 204, 316-327. [CrossRef]

25. Aljazzar, S.M.; Gurtu, A.; Jaber, M.Y. Delay-in-payments-A strategy to reduce carbon emissions from supply chains. J. Clean. Prod. 2018, 170, 636-644. [CrossRef]

26. Marchi, B.; Zanoni, S.; Zavanella, L.; Jaber, M. Supply chain models with greenhouse gases emissions, energy usage, imperfect process under different coordination decisions. Int. J. Prod. Econ. 2019, 211, 145-153. [CrossRef]

27. Daryanto, Y.; Wee, H.M.; Widyadana, G.A. Low Carbon Supply Chain Coordination for Imperfect Quality Deteriorating Items. Mathematics 2019, 7, 234. [CrossRef]

28. Gholami-Qadikolaei, A.; Mirzazadeh, A.; Tavakkoli-Moghaddam, R. Lead time and ordering cost reductions in budget and storage space restricted probabilistic inventory models with imperfect items. RAIRO-Oper. Res. 2015, 49, 215-242. [CrossRef]

29. Malik, A.I.; Sarkar, B. Optimizing a Multi-Product Continuous-Review Inventory Model With Uncertain Demand, Quality Improvement, Setup Cost Reduction, and Variation Control in Lead Time. IEEE Access 2018, 6, 36176-36187. [CrossRef]

30. Shin, D.; Guchhait, R.; Sarkar, B.; Mittal, M. Controllable lead time, service level constraint, and transportation discounts in a continuous review inventory model. RAIRO-Oper. Res. 2016, 50, 921-934. [CrossRef]

31. Malik, A.I.; Sarkar, B. A Distribution-Free Model with Variable Setup Cost, Backorder Price Discount and Controllable Lead Time. DJ J. Eng. Appl. Math. 2018, 4, 58-69. [CrossRef]

32. Tajbakhsh, M.M. On the distribution free continuous-review inventory model with a service level constraint. Comput. Ind. Eng. 2010, 59, 1022-1024. [CrossRef]

33. Sarkar, B.; Chaudhuri, K.S.; Moon, I. Manufacturing setup cost reduction and quality improvement for the distribution free continuous-review inventory model with a service level constraint. J. Manuf. Syst. 2015, 34, 74-82. [CrossRef]

34. Tayyab, M.; Sarkar, B.; Yahya, B. Imperfect Multi-Stage Lean Manufacturing System with Rework under Fuzzy Demand. Mathematics 2019, 7, 13. [CrossRef]

35. Sarkar, B.; Ullah, M.; Choi, S.-B. Joint Inventory and Pricing Policy for an Online to Offline Closed-Loop Supply Chain Model with Random Defective Rate and Returnable Transport Items. Mathematics 2019, 7, 497. [CrossRef]

36. Ullah, M.; Khan, I.; Sarkar, B. Dynamic Pricing in a Multi-Period Newsvendor Under Stochastic Price-Dependent Demand. Mathematics 2019, 7, 520. [CrossRef]

37. Pasandideh, S.H.; Niaki, S.T.A.; Rashidi, R. A two-echelon single-period inventory control problem under budget constraint. Int. J. Adv. Manuf. Technol. 2011, 56, 1205-1214. [CrossRef]

38. Jamshidi, R.; Ghomi, S.F.; Karimi, B. Flexible supply chain optimization with controllable lead time and shipping option. Appl. Soft Comput. 2015, 30, 26-35. [CrossRef]

39. Sarkar, B.; Saren, S.; Sarkar, M.; Seo, Y.W. A Stackelberg game approach in an integrated inventory model with carbon-emission and setup cost reduction. Sustainability 2016, 8, 1244. [CrossRef]

40. Malik, A.I.; Sarkar, B. Coordinating Supply-Chain Management under Stochastic Fuzzy Environment and Lead-Time Reduction. Mathematics 2019, 7, 480. [CrossRef]

41. Wook Kang, C.; Ullah, M.; Sarkar, M.; Omair, M.; Sarkar, B. A Single-Stage Manufacturing Model with Imperfect Items, Inspections, Rework, and Planned Backorders. Mathematics 2019, 7, 446. [CrossRef]

42. Scarf, H. A Min-max Solution of an Inventory Problem. In Studies in the Mathematical Theory of Inventory and Production; Stanford University Press: Stanford, CA, USA, 1958. 
43. Gallego, G.; Moon, I. The distribution free newsboy problem: Review and extensions. J. Oper. Res. Soc. 1993, 44, 825-834. [CrossRef]

44. Adby, P.; Dempster, M. Constrained optimization. In Introduction to Optimization Methods; Springer: Berlin, Germany, 1974; pp. 119-186.

45. Yang, X.-S. Nature-Inspired Optimization Algorithms; Elsevier: Amsterdam, The Netherlands, 2014.

46. Asghar, I.; Sarkar, B.; Kim, S.-j. Economic Analysis of an Integrated Production-Inventory System under Stochastic Production Capacity and Energy Consumption. Energies 2019, 12, 3179. [CrossRef]

47. Goyal, S.; Giri, B.C. The production-inventory problem of a product with time varying demand, production and deterioration rates. Eur. J. Oper. Res. 2003, 147, 549-557. [CrossRef]

48. Malik, A.I. Decision Support System of Optimum Bargaining and Cost Allocation Strategies under a Supply Chain Management. Ph.D. Thesis, Hanyang University, Seoul, Korea, 2019.

(C) 2020 by the authors. Licensee MDPI, Basel, Switzerland. This article is an open access article distributed under the terms and conditions of the Creative Commons Attribution (CC BY) license (http://creativecommons.org/licenses/by/4.0/). 